EESTI NSV TEADUSTE AKADEEMIA TOIMETISED. VII KÖIDE

BIOLOOGILINE SEERIA. 1958, NR. 1

ИЗВЕСТИЯ АКАДЕМИИ НАУК ЭСТОНСКОЙ ССР. ТОМ VII

СЕРИЯ БИОЛОГИЧЕСКАЯ. 1958, № 1

\title{
KALTSIUMI JA RAUA MÄÄRAMINE TURVASMULDADES KOMPLEKSOON III-GA
}

\author{
K. ILMOJA, V. JAASKA, A. TUULMETS
}

Viimasel ajal on analüütilises keemias laialdaselt kasutamisel 1945. aastal G. Schwarzenbachi poolt keemilisse analüüsi toodud kompleksoonid - ühendid, mis moodustavad paljude metallidega püsivaid kompleksühendeid. Nii kasutatakse kompleksoone mahtanalüüsis, kaalanalüüsis, kolorimeetrias ja polarograafias.

Köige laiemat rakendamist on seni leidnud kompleksoon III, mida tuntakse ka triloon-B jt. nimetuste all.

Kompleksoon III on etüleendiamiintetraäädikhappedinaatriumsool, valemiga

$$
\underset{\mathrm{HOOCH}}{\mathrm{HOOCH}_{2}}>\mathrm{N}-\mathrm{CH}_{2}-\mathrm{CH}_{2}-\mathrm{N}<\underset{\mathrm{CH}_{2} \mathrm{COONa}}{\mathrm{CH}_{2} \mathrm{COONa}}
$$

Kompleksoon III-nda rakendamisega on osutunud võimalikuks 15 katiooni ja mõnede anioonide mahtanalüütiline määramine $\left[{ }^{3}\right]$.

Metallidega reageerides moodustab kompleksoon III peaaegu momentaanselt väga vähe dissotsieerunud kompleksühendeid. Katioone sisaldavat lahust kompleksoon III-ga tiitrides seotakse katioonid ekvivalentpunktis täielikult kompleksoonkompleksi. Ekvivalentpunkti kindlakstegemiseks kasutatakse indikaatoreid, mis moodustavad määratava katiooniga intensiivselt värvunud komplekse. Viimased on vähempüsivad kui vastava metalli kompleks kompleksoon III-ga. Kompleksoon III seob endaga ka indikaatorkompleksis leiduva metalli iooni. Ekvivalentpunktis vabaneb indikaator, mille värvus on erinev indikaatorkompleksi värvusest. Toimub terav värvuse üleminek.

Erinevate metallide kompleksid kompleksoon III-ga on erineva püsivusega, viimane sõltub tugevasti keskkonna pH-st. See võimaldab paljudes uuritavates ainetes ühest ja samast lahusest ilma eraldamiseta tiitrida mitut katiooni, varieerides $\mathrm{pH}-\mathrm{d}$ ja kasutades segavate katioonide eemaldamiseks reaktiive, mis kas sadestavad mäăramist takistavad ioonid vōi viivad nad vähedissotsieerunud kompleksühenditesse.

ENSV TA Zooloogia ja Botaanika Instituudi laboratooriumis kasutatakse juba rida aastaid kompleksoon III-t looduslike vete analüüsimisel. Kirjanduses puudub turvasmuldade kompleksomeetrilise analüüsi metoodika. Vee analüüsi metoodika rakendamine turvasmuldadele ei osutunud võimalikuks, selletōttu oli vajalik käesoleva uurimuse teostamine.

\section{Kaltsiumi määramine}

Kaltsium moodustab kompleksoon III-ga värvitu, vees hästi lahustuva kompleksühendi, mis on eriti püșiv leeliseses keskkonnas.

Kõige laiemalt kasutatakse kaltsiumi määramisel ekvivalentpunkti kindlakstegemiseks mureksiidi (purpurhappeammooniumsoola) $\left[{ }^{2},{ }^{8},{ }^{12}\right]$. Purpurhappe anioon $\mathrm{I}^{-}$, mis leeliseses keskkonnas on siniviolett, reageerib kaltsiumi iooniga, moodustades punase kompleksühendi $\left[{ }^{2}\right]$ :

$$
\underset{\text { siniviolett }}{\mathrm{I}^{-}}+\mathrm{Ca}^{*} \rightarrow \underset{\text { punane }}{\mathrm{CaI}}
$$


Mureksiidi kompleks kaltsiumiga on vähem püsiv kui kompleksoon III-nda kompleks kaltsiumiga. Kompleksooniga tiitrimisel tõrjub kompleksoon III kaltsiumi ioonid mureksiidkompleksist välja. Ekvivalentpunktis seotakse kõik kaltsiumi ioonid kompleksoonkompleksi, kusjuures vabaneb indikaator [?].

$$
\underset{\text { punane }}{\mathrm{CaI}+\mathrm{H}_{2} \mathrm{Y}^{--}} \rightarrow \mathrm{CaY}_{\text {siniviolett }}^{--}+\mathrm{H}^{-}+\mathrm{I}^{-}
$$

Segavatest katioonidest tulevad kaltsiumi määramisel turvasmuldades kõne alla peamiselt raud ja mangaan.

Raua, samuti kolme ja neljavalentse mangaani ioonid takistavad indikaatori värvuse ülemineku jälgimist, sadenedes leeliseses keskkonnas hüdroksüüdidena välja.

Segavate katioonide kõrvaldamiseks on järgmised võimalused:

1) Siduda segavad ioonid kompleksi Na-dietüülditiokarbamaadiga ning ekstraheerida isoamüülalkoholiga $\left.{ }^{6}\right]$.

2) Siduda segavad ioonid kompleksi $\mathrm{KCN}$ abil, taandades raua eelnevalt kahevalentseks askorbiinhappe või hüdroksüülamiinhüdrokloriidiga $\left[{ }^{12}\right]$.

3) Sadestada raud ja alumiinium ammooniumhüdroksüüdiga kahekordselt $\mathrm{R}_{2} \mathrm{O}_{3}$-na.

4) Siduda raud, alumiinium ja mangaan kompleksi trietanoolamiini abil ["1']. See meetod võimaldab määrata kaltsiumi kuni $50 \mathrm{mg}$ raua, $50 \mathrm{mg}$ alumiiniumi ja $3 \mathrm{mg}$ mangaani juuresolekul.

5) Mangaani segavat mõju võib kõrvaldada selle taandamisega kahevalentseks iooniks hüdroksüülamiini või askorbiinhappe abil [ $\left.{ }^{12}\right]$.

Käesolevas töös kasutati segavate ioonide kõrvaldamiseks sadestamist ammooniumhüdroksüüdiga ja trietanoolamiini.

Kahekordne sadestamine ammooniumhüdroksüüdiga $\mathrm{R}_{2} \mathrm{O}_{3} \times \mathrm{H}_{2} \mathrm{O}$-na on aegaviitev ja tülikas. Lahusesse koguneb palju ammooniumi ioone, mis avaldavad puhverdavat mõju. Kaltsiumi määramiseks vajaliku keskkonnareaktsiooni ( $\mathrm{pH}$ 12) saamiseks tuleb lisada suured hulgad leelist.

Segavate ioonide mõju kõrvaldamisel osutus paremaks trietanoolamiin.

Kolmevalentse raua trietanoolkompleks on nõrkkollase kuni kollase värvusega, sõltudes raua kontsentratsioonist. Ekvivalentpunktis vabanenud indikaatori värvuse toon sõltub raudtrietanoolamiinkompleksi intensiivsusest ja magneesiumhüdroksüüdi sademe hulgast. Oldiselt on magneesiumhüdroksüüdi segav toime turvasmuldade proovides väike.

Mureksiidindikaatori ülemineku täpne jälgimine on võimalik ainult päevavalgusel. Elektrivalgusel töötamiseks soovitab Knight ${ }^{\left[{ }^{12}\right]}$ segaindikaatorit: 0,2 g mureksiidi ja 0,5 g naftoolrohelise-B segu.

Indikaatori värvuse ülemineku paremaks jälgimiseks on soovitav kasutada võrdluslahusena sama proovi ületiitritud lahust.

Töötati välja järgmine kaltsiumi määramise juhend.

5-8 g madalsoo- või $12-15 \mathrm{~g}$ rabaturvasmulda tuhastatakse $500^{\circ} \mathrm{C}$ juures, lahustatakse väheses hulgas kontsentreeritud $\mathrm{HCl}$-s ja lahuse maht viiakse $250 \mathrm{ml}$-ni.

5-25 ml nimetatud tuhalahust (olenevalt kaltsiumi kontsentratsioonist) pipeteeritakse $250 \mathrm{ml}$-sse koonilisse kolbi, lisatakse $2 \mathrm{ml}$ trietanoolamiinilahust, $10 \mathrm{ml} \mathrm{NaOH}$-lahust ja täiendatakse kogu lahuse maht destilleeritud veega umbes $100 \mathrm{ml}-\mathrm{ni}$. Lisatakse $10-15$ tilka mureksiidindikaatorit ja tiitritakse $0,01 M$ kompleksoon III-ga lilla värvuseni, kasutades võrdluslahust.

Kompleksoon III-nda täpne tiiter määratakse kaltsiumi standardlahusega sama juhendi järgi. 
Tabel 1

Kaltsiumi kompleksomeetrilise ja oksalaat-permanganomeetrilise määramise meetodite võrdlus

\begin{tabular}{|c|c|c|c|c|c|}
\hline \multirow{2}{*}{$\begin{array}{l}\text { Turvas- } \\
\text { mulla } \\
\text { proovi nr. }\end{array}$} & \multicolumn{3}{|c|}{$\begin{array}{l}\text { Tiitrimiseks kulunud } 0,01 \mathrm{M} \\
\text { kompleksoon III-t }\end{array}$} & \multicolumn{2}{|c|}{$\mathrm{CaO}(\%)$} \\
\hline & $\mathrm{ml}$ arv & diferents $\mathrm{ml}$ & keskm. ml & $\begin{array}{l}\text { komplekso- } \\
\text { meetriliselt }\end{array}$ & $\begin{array}{c}\text { oksalaat- } \\
\text { permangano- } \\
\text { meetriliselt }\end{array}$ \\
\hline 19. & $\begin{array}{l}14,27 \\
14,33 \\
14,31\end{array}$ & $\begin{array}{l}-0,03 \\
+0,03 \\
+0,01\end{array}$ & 14,30 & 6,17 & 6,21 \\
\hline 21 & $\begin{array}{l}14,93 \\
15,07 \\
14,98\end{array}$ & $\begin{array}{r}-0,05 \\
+0,08 \\
-0,01\end{array}$ & 14,99 & 5,97 & 5,96 \\
\hline 25 & $\begin{array}{l}13,18 \\
13,29 \\
13,32\end{array}$ & $\begin{array}{r}-0,08 \\
+0,03 \\
+0,06\end{array}$ & 13,26 & 5,25 & 5,27 \\
\hline 67 & $\begin{array}{l}7,72 \\
7,63 \\
7,60\end{array}$ & $\begin{array}{l}+0,07 \\
-0,02 \\
-0,05\end{array}$ & 7,65 & 2,98 & 3,02 \\
\hline 105 & $\begin{array}{l}7,05 \\
6,94 \\
7,01\end{array}$ & $\begin{array}{l}+0,05 \\
-0,06 \\
+0,01\end{array}$ & 7,00 & 3,56 & 3,48 \\
\hline 97 & $\begin{array}{l}14,28 \\
14,40 \\
14,37\end{array}$ & $\begin{array}{l}-0,07 \\
+0,05 \\
+0,02\end{array}$ & 14,35 & 0,42 & 0,43 \\
\hline 99 & $\begin{array}{l}3,20 \\
3,26 \\
3,16\end{array}$ & $\begin{array}{l}-0,01 \\
+0,05 \\
-0,05\end{array}$ & 3,21 & 0,31 & 0,31 \\
\hline 100 & $\begin{array}{l}4,26 \\
4,38 \\
4.29\end{array}$ & $\begin{array}{l}-0,05 \\
+0,07 \\
-0,02\end{array}$ & 4,31 & 0,21 & 0,21 \\
\hline 91 & $\begin{array}{l}6,27 \\
6,20 \\
6,25\end{array}$ & $\begin{array}{l}+0,03 \\
-0,04 \\
+0,01\end{array}$ & 6,24 & 0,13 & 0,14 \\
\hline 3 & $\begin{array}{l}22,45 \\
22,41 \\
22,36\end{array}$ & $\begin{array}{l}+0,04 \\
\pm 0,00 \\
\pm 0,05\end{array}$ & 22,41 & 5,40 & 5,46 \\
\hline 2 & $\begin{array}{l}14,00 \\
13,91 \\
14,04\end{array}$ & $\begin{array}{l}+0,02 \\
-0,07 \\
+0,06\end{array}$ & 13,98 & 3,96 & 4,02 \\
\hline 6 & $\begin{array}{l}14,55 \\
14,50 \\
14,54\end{array}$ & $\begin{array}{l}+0,02 \\
-0,03 \\
+0,01\end{array}$ & 14,53 & 3,88 & 3,92 \\
\hline
\end{tabular}




\section{REAKTIIVID}

1) Kompleksoon III-nda 0,01 $M$ tiiterlahus.

$37,21 \mathrm{~g}$ kompleksoon III-t lahustatakse destilleeritud vees ja valatakse $1000 \mathrm{ml}$-ses mõõtkolvis märgini; saadakse $0,1 \mathrm{M}$ lahus. Töötamiseks lahjendatakse lahust 10 korda. Tiiter määratakse kaltsiumi standardlahuse järgi. Tiiterlahuse säilitamise pudelid on soovitav eelnevalt läbi loksutada kompleksoon III-nda leeliselahusega, mis väldib reaktiivi hilisemat saastumist klaasist lahustuvate kaltsiumi ioonide poolt. Selliselt töödeldud nōudes säilib lahuse tiiter ühe kuu vältel muutumatuna.

2) Kaltsiumi standardlahus.

$1,7848 \mathrm{~g} \mathrm{CaCO}_{3}$ lahustatakse $10 \mathrm{ml}$-s $15 \%$-lises $\mathrm{HCl}$-s ja lahjendatakse destilleeritud veega $1000 \mathrm{ml}$ mōōtkolvis märgini. $1 \mathrm{ml}$ lahust sisaldab $1,00 \mathrm{mg} \mathrm{CaO}$.

3) Trietanoolamiini $10 \%$-line vesilahus.

4) $\mathrm{NaOH} 10 \%$-line vesilahus.

5) Mureksiidindikaator.

Mureksiid laguneb kergesti ōhuhapniku käes, mistōttu tuleb indikaatorlahus iga päev uuesti valmistada. Selleks loksutatakse umbes $0,2 \mathrm{~g}$ mureksiidi vähese $(25 \mathrm{ml})$ destilleeritud veega ja lastakse lahustumata värvaine settida. Tiitrimisel kasutatakse sademe pealt dekanteeritud lahust.

Indikaatorina vōib kasutada ka mureksiidi tahket segu NaCl-ga $(1: 100)$, mis on püsiv, kuid sel juhul on indikaatori täpne doseerimine takistatud.

Võrdlevad andmed kaltsiumi määramisel turvasmullaproovides kompleksomeetrilise ja mahtanalüütilise permanganomeetrilise meetodiga on antud tabelis 1 .

\section{Raua määramine}

Schwarzenbachi $\left.{ }^{12}\right]$ järgi moodustab kompleksoon III, sõltuvalt pH-st, rauaga järgmisi komplekse:

\begin{tabular}{cll}
$\mathrm{pH}$ & Kompleks & \multicolumn{1}{c}{$\mathrm{pK}$} \\
$1,5-4$ & $(\mathrm{FeY})^{-}$ & $7,9 \cdot 10^{-25}$ \\
$5-6$ & $(\mathrm{FeYOH})^{-2}$ & $3,5 \cdot 10^{-7}$ \\
$6-9$ & $\left(\mathrm{FeY}(\mathrm{OH})_{2}\right)^{-3}$ & $2,9 \cdot 10^{-5}$ \\
10 & $\mathrm{Fe}(\mathrm{OH})_{3}$ & $\mathrm{Lp}=3,8 \cdot 10^{-38}$
\end{tabular}

Siit nähtub, et kasulikum on tiitrida rauda kompleksooniga hapus keskkonnas ( $\mathrm{pH} 1,5-4$ juures), sest sel juhul on vastav kompleks rauaga püsivam ja indikaatorkompleksi asendumine kompleksoonkompleksiga toimub kergemini. Leeliseses keskkonnas ei ole raua tiitrimine võimalik tema väljasadenemise tõttu hüdroksüüdina. Et raua kompleks kompleksooniga $\mathrm{pH}$ $1,5-4$ puhul on püsivam kui teiste katioonide vastavad kompleksid, siis võib rauda tiitrida ka teiste katioonide juuresolekul. Kirjanduse andmeil $\left.{ }^{4}, 5\right]$ ei sega raua tiitrimist $\mathrm{Ca}{ }^{*}, \mathrm{Mg}^{*}, \mathrm{Mn}^{\prime}, \mathrm{Cl}^{-}, \mathrm{SO}_{4}{ }^{--}, \mathrm{PO}_{4}{ }^{---} . \mathrm{Cu}{ }^{\circ}$ hakkab segama alates $2 \mathrm{mg}$-st, $\mathrm{Zn}^{-}$" alates $60 \mathrm{mg}$-st.

Ekvivalentpunkti määramiseks on indikaatoritena kasutatud sulfosalitsüülhapet $\left[{ }^{4},{ }^{7},{ }^{9}\right]$, salitsüülhapet ${ }^{[5]}$, tirooni (dikaalium $-1,2-$ dihüdroksübenso $-3,5$ - disulfaat) $\left[{ }^{5}\right]$ ja rodaniidi $\left[{ }^{1,10}\right]$.

Käesoleva töö autorid katsetasid indikaatoritena raua tiitrimisel kaaliumrodaniidi ja sulfosalitsüülhapet.

Rodaniidindikaatori positiivseteks omadusteks on tema spetsifilisus ja 
tundlikkus $\mathrm{Fe}{ }^{\prime}$ ' ioonide suhtes. Mainitud indikaatoril esineb ka terve rida olulisi puudusi. Ekvivalentpunktis toimub värvuse järkjärguline ja aeglane üleminek punasest kollaseks või oranžiks, olenevalt raua kontsentratsioonist, kusjuures lōpp-punkt on raskesti märgatav. Ekvivalentpunkti täpsemaks kindlakstegemiseks lisatakse orgaanilist solventi isoamüülalkoholi või isoamüülalkoholi ja eetri segu (1:1). Sel juhul ekstraheeritakse raua rodaniidkompleksi viimased jäljed solvendi kihti ning värvuse üleminek on täpsemalt jälgitav. Orgaanilise solvendi kasutamise puuduseks on see, et ta aeglustab veelgi reaktsiooni ja ühtlasi tiitrimist. Puuduseks on ka rodaniidi taandav mõju Fe ${ }^{\cdots}$ suhtes, mille vältimiseks tuleb lisada oksüdeerijat.

Rodaniidindikaatorist paremini saab raua kompleksomeetrilisel tiitrimisel kasutada sulfosalitsüülhapeindikaatorit, mille mõjul toimub värvuse üleminek kiiremini ja on paremini jälgitav. Samuti ei ole sulfosalitsüülhapeindikaatoril taandavat toimet $\mathrm{Fe}$ " suhtes. Indikaatoril on happelises keskkonnas mõju $\mathrm{Fe}^{\cdots}$ ' ioonidele.

Keskkonna happesuse tõstmine vähendab järsult tiitrimise tulemusi. Soovitatav $\mathrm{pH}$ tiitrimisel on $1,4-1,6\left[^{1}\right]$ või $2\left[^{5,7}\right]$.

Paljud autorid kuumutavad tiitritavat lahust tiitrimise kiirendamiseks ja värvuse teravamaks üleminekuks ekvivalentpunktis. Käesoleva töö teostamisel leiti, et ka külmalt tiitrimine annab häid tulemusi, kui aeglustada tiitrimist vahetult enne ekvivalentpunkti jõdmist. Suuremate rauahulkade (rohkem kui $25 \mathrm{mg}$ ) puhul ei ole indikaatori värvuse üleminek hästi jälgitav.

Töötati välja järgmine $r$ a u a $m$ ä är a mis e j u he n d.

Võetakse $5-25 \mathrm{ml}$ turvasmulla tuhast valmistatud soolhappelist lahust (vrd. kaltsiumi määramise juhend), millele lisatakse tilkhaaval $\mathrm{NaOH}$ lahust, kuni kollase rauahüdroksüüdi tekkimiseni (värvuse üleminekut võib jälgida ka kongo paberil). Lahuse maht viiakse destilleeritud vee lisandamisega umbes $50 \mathrm{ml}$-ni; lisatakse veel 1 tilk kontsentreeritud $\mathrm{HCl}$ ja 3 tilka sulfosalitsüülhapeindikaatorit ning tiitritakse $0,01 \mathrm{M}$ kompleksoon III-ga, kuni värvus läheb üle punasest kollaseks.

\section{REAKTIIVID}

1) Kompleksoon III-nda 0,01 M tiiterlahus (vrd. 1k. 42).

2) Raua standardlahus.

$6,039 \mathrm{~g} \mathrm{NH}_{4} \mathrm{Fe}\left(\mathrm{SO}_{4}\right)_{2} \cdot 12 \mathrm{H}_{2} \mathrm{O}$ lahustatakse $1000 \mathrm{ml}$-lises mõōtkolvis $\mathrm{H}_{2} \mathrm{SO}_{4}$-ga hapustatud destilleeritud vees ja täidetakse destilleeritud veega märgini. $1 \mathrm{ml}$ lahust sisaldab $1,00 \mathrm{mg} \mathrm{Fe}_{2} \mathrm{O}_{3}$.

3) $\mathrm{NaOH} 10 \%$-line vesilahus.

4) $\mathrm{HCl}$ (konts.).

5) Sulfosalitsüülhapeindikaatori $20 \%$-line vesilahus.

6) Kongo paber.

Kompleksomeetrilise meetodi võrdluseks kasutati jodomeetrilist meetodit ja rabaturvasmuldade puhul kolorimeetrilist sulfosalitsüülhappemeetodit. Tulemused on kokku võetud tabelis 2 .

ENSV TA Zooloogia ja Botaanika Instituudi laboratooriumis tehtud eelkatsed näitavad, et turvasmuldades on peale raua ja kaltsiumi võimalik kompleksoon III-nda abil määrata veel magneesiumi ja alumiiniumi. Täpne metoodika selleks on väljatöötamisel, 
Tabel 2

Raua sulfosalitsüülhappe kompleksomeetrilise ja jodomeetrilise või kolorimeetrilise määramise meetodite võrdlus

\begin{tabular}{|c|c|c|c|c|c|}
\hline \multirow{2}{*}{$\begin{array}{l}\text { Turvas- } \\
\text { mulla } \\
\text { proovi nr. }\end{array}$} & \multicolumn{3}{|c|}{$\begin{array}{l}\text { Tiitrimiseks kulunud } 0,01 \mathrm{M} \\
\text { kompleksoon III-t }\end{array}$} & \multicolumn{2}{|c|}{$\mathrm{Fe}_{2} \mathrm{O}_{3}$ turvasmullas $(\%)$} \\
\hline & $\mathrm{ml}$ arv & diferents $\mathrm{ml}$ & keskm. ml & $\begin{array}{l}\text { komplekso- } \\
\text { meetriliselt }\end{array}$ & $\begin{array}{c}\text { jodomeetrili- } \\
\text { liselt }\end{array}$ \\
\hline 17 & $\begin{array}{l}8,45 \\
8,50 \\
8,50\end{array}$ & $\begin{array}{r}-0,03 \\
+0,02 \\
+0,02\end{array}$ & 8,48 & 1,77 & 1,82 \\
\hline 21 & $\begin{array}{l}11,38 \\
11,42\end{array}$ & $\begin{array}{l}-0,02 \\
+0,02\end{array}$ & $11 ; 40$ & 2,59 & 2,62 \\
\hline 26 & $\begin{array}{l}8,16 \\
8,23 \\
8,19\end{array}$ & $\begin{array}{r}-0,03 \\
+0,04 \\
\pm 0,00\end{array}$ & 8.19 & 1,84 & 1,88 \\
\hline 67 & $\begin{array}{l}17,18 \\
17,23 \\
17,20\end{array}$ & $\begin{array}{r}-0,02 \\
+0,03 \\
\pm 0,00\end{array}$ & 17,20 & 3,90 & 3,85 \\
\hline 68 & $\begin{array}{l}7,75 \\
7,80 \\
7,73\end{array}$ & $\begin{array}{l}-0,01 \\
+0,04 \\
-0,03\end{array}$ & 7,76 & 1,68 & 1,68 \\
\hline 79 & $\begin{array}{l}15,45 \\
15,43 \\
15,48\end{array}$ & $\begin{array}{l} \pm 0,00 \\
\pm 0,02 \\
+0,03\end{array}$ & 15,45 & 3,55 & 3,55 \\
\hline 106 & $\begin{array}{l}5,72 \\
5,75 \\
5,76\end{array}$ & $\begin{array}{l}-0,02 \\
+0,01 \\
+0,02\end{array}$ & 5,74 & 1,26 & 1,27 \\
\hline & & & & & $\begin{array}{l}\text { kolorimeetri- } \\
\text { line sulfosalit- } \\
\text { süülhape }\end{array}$ \\
\hline 91 & $\begin{array}{l}5,29 \\
5,22\end{array}$ & $\begin{array}{l} \pm 0,04 \\
+0,04 \\
-0,03\end{array}$ & 5,25 & 0,16 & 0,17 \\
\hline 93 & $\begin{array}{l}1,56 \\
1,51 \\
1,47\end{array}$ & $\begin{array}{l}+0,05 \\
\pm 0,00 \\
\pm 0,03\end{array}$ & 1,51 & 0,09 & 0,09 \\
\hline 95 & $\begin{array}{l}5,50 \\
5,55 \\
5,52\end{array}$ & $\begin{array}{l}-0,02 \\
+0,03 \\
\pm 0,00\end{array}$ & 5,52 & 0,31 & 0,31 \\
\hline 97 & $\begin{array}{l}3,92 \\
3,98 \\
3,93\end{array}$ & $\begin{array}{l}-0,02 \\
+0,04 \\
-0,01\end{array}$ & 3,94 & 0,11 & 0,11 \\
\hline 98 & $\begin{array}{l}5,90 \\
5,94 \\
5,88\end{array}$ & $\begin{array}{l}-0,01 \\
+0,04 \\
-0,03\end{array}$ & 5,91 & 0,27 & 0,26 \\
\hline
\end{tabular}




\title{
Kokkuvõte
}

Käesoleva probleemi uurimisel töötati välja meetodid kaltsiumi ja raua kompleksomeetriliseks määramiseks turvasmuldades.

Kuna määramised toimuvad otseselt alglahusest, ületavad need meetodid kiiruse ja lihtsuse poolest mitmekordselt vastavad klassikalised mahtanalüütilised meetodid.

Kompleksomeetriliste meetodite täpsus on mõnevõrra väiksem, võrreldes teiste kaltsiumi ja raua määramisel seni kasutatud meetoditega, kuid nad on täiesti küllaldased massanalüüsideks.

\section{KIRJANDUS}

1. Б а шки р ге в а А. А. и Я к и ме ц К. Б., Применение трилона Б для определения железа в природных водах. Завод. лабор., т. 21, 1955, № 5, lk. 533.

2. Пршибил P. (Přibil, R.), Комплексоны в химическом анализе. Москва, 1955.

3. С иняков а С. И., Комплексоны и их значение в аналитической химин. Журн. анал. хим., т. 10, 1955, № 3.

4. У с атенко Ю. И. и Ми х й ло в а Л. И., Определение железа в железных рудах и агломерате при помощи трнлона Б. Завод. лабор., т. 21,1955 , № 10 , lk. 1149 .

5. Cheng, K. L., Bray, R. H., Kurtz, T., Determination of Total Iron in Soils by EDTA Titration. Analytical Chem., vol. 25, 1953, lk. 347.

6. Cheng, K. L., Melsted, S. W., Bray, R. H., Removing Interfering Metals in the Versenate Determination of Calcium and Magnesium Soil. Sci., vol. 75, 1953. lk. 37 .

7. Fl a s ch k a, H., Mikrochemische Titration mit Ac. DTE Mikrochemie, 39, 1952, 1k. 38.

8. Fla schka, H., Uber die Verwendung Komplexon in der Massanalyse. Fortschritte der Chem. Forschung, 3. Band, 2. Heft, 1955, lk. 254-300.

9. Fla sch ka, H. u. A b d in e, H., Zur komplexometrischen Titration von Aluminium und Eisen und der Summe beider. Zeitschrift Anal. Chem., 152, 1, 1956, lk. 77.

10. Lydersen, D. u. Gjens, O., Titration von Eisen III Salz mit Versenat. Zeitschrift für Anal. Chem., 138, 1953, lk. 249-256.

11. P r i bi l, R., Komplexometricke titrace (chelatometrie) IV stineni heiniku, zeleza a manganu pri titraci na murexid. Chem. listy, 47, 9, 1953; Реф. Журн. Хим. Реферат. 29315 (1954).

12. S chwarzenbach, G., Die komplexometrische Titration. Stuttgart, 1955.
Eesti NSV Teaduste Akadeemia
Zooloogia ja Botaanika Instituut
Saabus toimetusse
1. VII 1957

\section{ОПРЕДЕЛЕНИЕ КАЛЬЦИЯ И ЖЕЛЕЗА В ТОРФЯНЫХ ПОЧВАХ КОМПЛЕКСОНОМ III (ТРИЛОНОМ Б)}

\author{
К. А. Ильмоя, В. Э. Яаска, А. В. Туулметс
}

Резюме

В настоящем исследовании разработан метод определения кальция и железа путем титровання комплексоном III. При определении кальция с помощью мурексндиндикатора для устранения влияний вредных ионов наилучшим оказалось применение триэтаноламина.

При определении железа титрованием комплексоном хорошие результаты получены при наличии индикатора (сульфосалициловая кислота) без нагревания. При малых количествах железа (менее $25 \mathrm{mr}$ ) и медленном титровании перед концом переход окраски от красной до желтой особенно резок. 


\title{
Методика определения
}

5-15 г торфяной почвы озоляют при температуре $500^{\circ} \mathrm{C}$. Золу растворяют в нескольких миллилитрах концентрированной $\mathrm{HCl}$ и объем раствора доводят до 250 мл.

Для определения к альц и я наливают пипеткой 5-25 мл раствора в 250 миллилитровую коническую колбу, прибавляют 2 мл 10\%-го раствора триэтаноламина, 10 мл $10 \%$-го раствора $\mathrm{NaOH}$ и доводят объем приблизительно до 100 мл. Затем добавляют 10-15 капель мурексидиндикатора (насыщенный водный раствор мурексида) и титруют $0,01 \mathrm{M}$ комплексоном III до фиолетовой окраски, применяя для сравнения перетитрованный раствор той же пробы. Сравнительные данные іпо определению кальция комплексометрическим методом и обычным оксалат-перманганатным методом приведены в табл. 1 .

Для о п реде ле н и я жел е з а берут пипеткой 5-25 мл раствора золы, к нему добавляют по каплям 10\%-го раствора $\mathrm{NaOH}$, пока появится слабый осадок гидроокиси железа или до перехода окраски на бумаге конго. Затем добавляют одну каплю концентрированной $\mathrm{HCl}$ и три капли $20 \%$-го раствора сульфосалициловой кислоты и титруют $0,01 \mathrm{M}$ раствором комплексона III до перехода окраски от красной до желтой. Сравнительные данные по определению железа комплексометрическим и иодометрическим методом приведены в табл. 2.

Ннститут зоологии и ботаники

Академии наук Эстонской ССР

Поступила в редакцию

1 VII 1957

\section{DIE BESTIMMUNG DES KALZIUM- UND EISENGEHALTS IN TORFBODEN VERMITTELST KOMPLEXON III}

\author{
K. Ilmoja, V. Jaaska, A. Tuulmets \\ Zusammenfassung
}

Die vorliegende Arbeit untersucht die Möglichkeit, den Kalzium- und Eisengehalt in Torfböden mittels Komplexon III zu bestimmen.

Beim Titrieren des Kalziums mit Komplexon III unter Zusatz von Murexid-Indikator diente Triethanolamin als das beste Maskierungsmittel der störenden Ionen.

Bei der Bestimmung des Eisengehalts ergab kaltes Titrieren mit Komplexon III unter Zusatz von Sulfosalicylsäure gute Resultate. Der Farbenübergang des Indikators war bei geringen Eisenkonzentrationen (weniger als $25 \mathrm{mg}$ ) besonders scharf.

Für komplexometrische Bestimmungen werden folgende Vorschriften gegeben:

5-15 g Torfboden wird bei $500^{\circ} \mathrm{C}$ verascht, in einer kleinen Menge konzentrierter $\mathrm{HCl}$ aufgelöst und mit destilliertem Wasser auf $250 \mathrm{ccm}$ ergänzt.

Zur Bestimmung des Kalziums wird von der Aschenlösung 5-25 ccm genommen, mit $10 \mathrm{ccm} 10 \%$-iger $\mathrm{NaOH}$ und $2 \mathrm{ccm} 10 \%$-iger Triethanolaminlösung versetzt, mit destilliertem Wasser auf ca, $100 \mathrm{ccm}$ ergänzt und unter Zusatz von 10-15 Tropfen MurexidIndikator mit $0,01 \mathrm{M}$ Komplexon III bis zur Violettfärbung titriert.

Zur Bestimmung des Eisens wird $5-25 \mathrm{ccm}$ Aschenlösung genommen und $10 \%$-ige $\mathrm{NaOH}$ tropfenweise hinzugefügt, bis zur Ausscheidung von $\mathrm{Fe}(\mathrm{OH})_{3}$ oder bis zum Farbenumschlag des Kongopapiers. Nach Zugabe von 1 Tropfen konzentrierter $\mathrm{HCl}$ zur Auflösung des $\mathrm{Fe}(\mathrm{OH})_{3}$ und von 3 Tropfen 20\%-iger Sulfosalicylsäure-Wasserlösung wird die Lösung mit $0,01 \mathrm{M}$ Komplexon III bis zum Farbwechsel von rot zu gelb titriert.

Angaben über die Vergleichsbestimmungen finden sich in Tab. 1 und 2.

Institut für Zoologie und Botanik

der Akademie der Wissenschaften der Estnischen SSR
Eingegangen am 1. Juli 1957 